\title{
ANALISIS WAKTU TUNGGU PELAYANAN DAN LOKASI USAHA SEBAGAI ANTECEDENT KEPUASAN PELANGGAN PADA RUMAH MAKAN GEMAH RIPAH PURWAKARTA
}

\begin{tabular}{|c|c|}
\hline \multicolumn{2}{|c|}{$\begin{array}{c}\text { Oleh : } \\
\text { Amna Mawardi } \\
\text { Program Studi Manajemen - STIE DR KHEZ Muttaqien } \\
\text { Email : amnamawardi@gmail.com }\end{array}$} \\
\hline Article Info & Abstract \\
\hline $\begin{array}{l}\text { Article History : } \\
\text { Received } 18 \text { August }-2021 \\
\text { Accepted 02 Sept - } 2021 \\
\text { Available Online } 25 \text { Sept }- \\
\text { 2021 }\end{array}$ & $\begin{array}{l}\text { This research was conducted to find out what factors can } \\
\text { influence consumers satisfaction. In this study used two } \\
\text { independent variables Waiting Time (X1), and Location (X2), } \\
\text { while Customer Satisfaction (Y) as the dependent variable. After } \\
\text { reviewing the literature and formulating hypotheses, data } \\
\text { collection was carried out by distributing questionnaires to } 97 \\
\text { consumers at Gemah Ripah Purwakarta Restaurant who had } \\
\text { carried out the purchase using non probility sampling techniques. } \\
\text { For analysis and elaboration of data using SPSS version } 21 \text {. Then } \\
\text { there are several tests performed in analyzing data, such as } \\
\text { measuring instruments, classical assumption tests, multiple linear } \\
\text { regression analysis and hypothesis testing. Based on the results of } \\
\text { the analysis found that the two independent variables have a } \\
\text { significant and positive effect on the dependent variable. Waiting } \\
\text { time variable has a positive effect of } 0.488 \text { with a significance level } \\
\text { of 0,000. Location variables have a positive effect of } 0.566 \text { with } \\
\text { a significance level of 0.000. Adjusted } R \text { Square of the three } \\
\text { variables is } 0.662 \text { or } 66.2 \% \text { which means that the two variables are } \\
\text { able to explain the variation in the dependent variable of } 66.2 \\
\text { percent with } 33.8 \text { percent explained by other variables not used in } \\
\text { this study. }\end{array}$ \\
\hline $\begin{array}{l}\text { Keyword: } \\
\text { Waiting Time, Location, } \\
\text { Customer Satisfaction }\end{array}$ & \\
\hline
\end{tabular}

\section{PENDAHULUAN}

Era globalisasi saat ini menuntut pelaku usaha untuk lebih kreatif dan inovatif karena hal tersebut dapat memberikan nilai lebih kepada konsumen. Pelaku usaha harus bisa menemukan berbagai strategi yang tepat untuk mencapai keunggulan yang kompetitif,dengan harapan bisa mempertahankan pasar dan memenangkan persaingan (Muhtarom, Warso, \& Hasiolan, 2015). Salah satu bisnis yang sedang berkembang saat ini adalah bisnis kuliner (makanan). Bisnis kuliner berkembang mulai dari kelas kaki lima, warung sederhana, cafe, hingga restoran mewah, masing-masing tentu perlu memiliki keistimewaan agar diperhatikan oleh konsumen. Pertumbuhan jumlah restoran atau rumah makan di Jawa Barat sendiri memang menunjukan tren pertumbuhan yang positif. Salah satunya di Kabupaten Purwakarta. Badan Pusat Statistik Jawa Barat menunjukkan bahwa jumlah restoran atau rumah makan di Purwakarta mengalami peningkatan tiap tahunnya. Tahun 2015 terdapat 46 unit, meningkat pada tahun 2016 menjadi 65 unit atau naik $29,23 \%$, dan kembali meningkat signifikan pada tahun 2017 menjadi 102 unit atau $36,27 \%$. Hal ini memberikan gambaran kondisi restoran atau rumah makan mengalami persaingan yang ketat.

Namun Rumah Makan Gemah Ripah Purwakarta, yang berada di Jl. Pramuka No.10, RT.14/RW.6, Bunder, Jatiluhur. Faktanya diketahui bahwa rumah makan gemah ripah purwakarta pengunjungnya sepi dibandingkan dengan rumah makan lain. Ini mengindikasikan adanya 
ketidakpuasan konsumen terhadap rumah makan gemah ripah purwakarta.

Waktu tunggu dinilai dapat mempengaruhi kepuasan pelanggan. Sebagian besar pelanggan tidak suka menunggu lama untuk mendapatkan layanan. Pelanggan modern lebih memilih untuk pergi ke salah satu restoran cepat saji dari pada akan membeli makanan di rumah makan. Jika waktu tunggu lebih lama, pelanggan menjadi tidak sabar (Polas, Rahman, Miah, \& Hayash,

2018). Hasil penelitian menunjukkan bahwa ada hubungan antara waktu tunggu yang dirasakan dan kepuasan waktu tunggu. Artinya, seiring meningkatnya waktu tunggu, tingkat kepuasan turun. Sebelum pergi ke restoran mana pun, pelanggan memperkirakan waktu tunggu. Jika waktu tunggu aktual menjadi lebih besar dari waktu yang dirasakan, maka menjadi tidak puas. Jadi, waktu tunggu yang lama mungkin di konversi menjadi kurang memuaskan (Polas dkk., 2018).

Seperti yang diketahui, pelanggan selalu mengambil layanan secepat dan senyaman mungkin. Ketika itu membutuhkan waktu lebih lama, pelanggan akan menjadi membosankan. Oleh karena itu, pelanggan mungkin menjadi puas ketika mereka mendapatkan produk diluar waktu tunggu yang diharapkan (Dabholkar, 2015). Oleh karena itu, waktu tunggu pelanggan terkait langsung dengan kepuasan pelanggan. Setiap upaya untuk mengurangi waktu tunggu pelanggan akan meningkatkan kepuasan pelanggan (Iqbal, Whitman, \& Malzahn, 2012).

Hasil penelitian serupa ditunjukkan Lustinayanti \& Kurniawati (2017) bahwa ada pengaruh signifikan antara waktu tunggu terhadap kepuasan pelanggan. Seperti yang diketahui, pelanggan selalu mengambil layanan secepat dan senyaman mungkin. Ketika itu membutuhkan waktu lebih lama, pelanggan akan menjadi membosankan. Oleh karena itu, pelanggan mungkin menjadi puas ketika mereka mendapatkan produk diluar waktu tunggu yang diharapkan (Dabholkar, 2015). Oleh karena itu, waktu tunggu pelanggan terkait langsung dengan kepuasan pelanggan. Setiap upaya untuk mengurangi waktu tunggu pelanggan akan meningkatkan kepuasan pelanggan (Iqbal, Whitman, \& Malzahn, 2012).

Lokasi juga dapat menjadi prediktor penting dalam meningkatkan kepuasan pelanggan. Lokasi diartikan sebagai tempat dimana orang-orang biasa berkunjung (Heizer \& Render, 2011). Dalam memilih lokasi, konsumen biasanya memperhatikan akses, yaitu kemudahan untuk menjangkau.

Visibilitas yaitu kemudahan untuk dilihat. Lalu lintas, ada dua hal yang diperhatikan pelanggan, yaitu banyaknya orang yang lalu lalang bisa memberikan peluang yang besar terjadi impuls buyin dan kepadatan serta kemacetan bisa menjadi hambatan. Tempat parkir yang luas dan aman. Ekspansi aitu tersedia tempat yang luas untuk perluasan di kemudian hari, dan peraturan pemerintah (Tjiptono \& Chandra, 2016).

Faktor penting bagi kelangsungan hidup perusahaan yaitu memuaskan kebutuhan konsumen. Waktu tunggu yang baik memberikan suatu dorongan positif kepada konsumen sehingga dapat meningkatkan kepuasan pelanggan. Lokasi yang mudah dijangkau dan pemilihan tempat yang tepat diperlukan pertimbangan cermat agar dapat menarik minat konsumen.

\section{KAJIAN PUSTAKA PEGEMBANGAN HIPOTESIS}

\section{Pemasaran}

Pemasaran dapat diartikan mencakup usaha perusahaan yang dimulai dengan mengidentifikasi kebutuhan konsumen yang perlu dipuaskan atau mampu memenuhi kebutuhan dan keinginannya, menentukan produk yang hendak di produksi, menentukan harga produk yang sesuai, menentukan cara promosi dan penyaluran atau penjualan produk tersebut.

Didalam ruang lingkup pemasaran terdapat istilah yang dinamakandengan bauran pemasaran (marketing mix). Bauran pemasaran merupakan serangkaian variabel pemasaran yang harus dikuasai dan dipahami oleh

perusahaan untuk dapat mencapai tujuan perusahaan atau perangkat alat pemasaran yang digunakan perusahaan

untuk mengejar tujuan pemasarannya

(Kotler \& Keller, 2016).

Dalam bauran pemasaran terdapat seperangkat alat pemasaran yang dikenal dalam istilah 4P, yaitu product (produk), price (harga), place (tempat), dan promotion (promosi), dan istilah 7P yaitu product, price, place, promotion, people, physical evidence, and process (Kotler \& Amstrong,

2016).

\section{Waktu tunggu}

Menurut Heizer \& Render (2011), waktu tunggu juga diartikan sebagai orang-orang atau barang dalam barisan yang sedang menunggu untuk dilayani. Tujuan teori waktu tunggu adalah meneliti kegiatan antrian dan fasilitas pelayanan dalam kondisi acak dari suatu sistem antrian yang terjadi. Faktor-faktor yang mempengaruhi waktu tunggu adalah faktor persepsi yang mempengaruhi waktu tunggu adalah atribut penumpang (usia, jenis kelamin, jumlah mitra, waktu berkunjung) dan lingkungan objektif (cuaca, fasilitas 
menunggu, informasi tunggu tersedia, program interaktif di tempat, jumlah orang terdekat) (Wu, Lu, \& Ge, 2013). Menurut Bielen dan Demoulin (2007 dalam Kristanti dkk., 2015) waktu tunggu memiliki tiga dimensi, yaitu: pre-process stage, in-process stage and post- process stage.

\section{Lokasi}

Lokasi juga diartikan letak, tempat atau penempatan suatu benda, keadaan pada permukaan bumi. Lokasi dalam hubungannya dengan pemasaran adalah tempat yang khusus dan unik dimana lahan tersebut dapat digunakan untuk berbelanja. Lokasi berpengaruh terhadap dimensi-dimensi strategik, seperti fleksibilitas, competitive positioning, manajemen permintaan, dan focus strategic (Tjiptono \& Chandra, 2012). Jika perusahaan berhasil memperoleh dan mempertahankan lokasi yang strategis, maka itu dapat menjadi rintangan yang efektif bagi para pesaing untuk mendapatkan akses ke pasar (Tjiptono \& Chandra, 2012).

Faktor yang mempengaruhi lokasi yang menjadi pertimbangan pedagang adalah: site characteristic (karakteristik dari sudut lokasi), location characteristic (karakteristik lokasi perdagangan dari sudut toko), dan restriction and cost (estimasi penjualan yang bisa didapatkan dari lokasi toko) (Levy \& Weitz, 2012). Adapun Pemilihan lokasi memerlukan pertimbangan beberapa dimensi lokasi berikut (Tjiptono \& Chandra, 2012): akses. Visibilitas dan lalu lintas.

Indikator yang digunakan sebagai alat ukur lokasi rumah makan meliputi: tempat duduk rumah makan nyaman bagi para konsumen, arus lalu lintas menuju rumah makan lancar, kondisi lingkungan rumah makan nyaman, area parkir rumah makan luas, dan dekorasi interior rumah makan indah (Muhtarom dkk., 2015).

\section{Kepuasan Pelanggan}

Kepuasan merupakan perasaan senang atau kecewa seseorang yang timbul karena membandingkan kinerja yang dipersepsikan produk (atau hasil) terhadap ekspektasinya. Jika kinerja gagal memenuhi ekspektasi pelanggan akan tidak puas. Jika kinerja sesuai ekspektasi, pelanggan akan puas, jika kinerja melebihi ekspektasi, maka pelanggan akan sangat puas atau senang (Kotler \& Keller, 2016). Faktor yang mempengaruhi kepuasan pelanggan yaitu, quality, reliability, responsiveness, access, courtesy, communication, credibility. (Lovelock \& Wright, 2011) Dimensi kepuasan pelanggan dibagi menjadi beberapa macam seperti harapan, Penyampaian produk atau jasa yang dirasakan, konfrimasi/diskomfirmasi, perilaku mengeluh. Pengukuran kepuasan pelanggan dibagi menjadi empat metode yaitu, sistem keluhan dan saran, ghost shopping, lost customer analysis dan survei kepuasan pelanggan. Hipotesis

a) Waktu tunggu dan lokasi berpengaruh secara parsial terhadap kepuasan pelanggan pada Rumah Makan Geman Ripah Purwakarta.

b) Waktu tunggu dan lokasi berpengaruh secara simultan terhadap kepuasan pelanggan pada Rumah Makan Geman Ripah Purwakarta.

\section{METODE PENELITIAN}

Penelitian ini menggunakanpendekatan kuantitatif deskriptif dimana pendekatan penelitian menggunakan data berupa angkaangka hasil jawaban survei yang disebarkan oleh sampel penelitian.

Populasi dalam penelitian ini adalah pengunjung rumah makan yang melakukan kegiatan bisnis dan kegiatan lainnya yang berkaitan dengan penggunaan jasa rumah makan. Sampel dalam penelitian ini menggunakan teknik non probability sampling dengan teknik purpossive sampling.

\section{HASIL DAN PEMBAHASAN}

Pengaruh waktu tunggu terhadap kepuasan pelanggan pada Rumah Makan Gemah Ripah Purwakarta

Berdasarkan uji $\mathrm{T}$ yang telah dilakukan diketahui nilai $\mathrm{T}$ hitung untuk variabel waktu tunggu (X1) adalah sebesar $\mathrm{T}$ hitung 2,557 didukung dengan nilai siginifikan 0,002 yang lebih kecil dari 0,05 atau 5\%, maka $\mathrm{H} 0$ ditolak $\mathrm{H} 1$ diterima, sehingga dapat dikatakan variabel waktu tunggu (X1) mempunyai pengaruh yang signifikan terhadap kepuasan pelanggan (Y).

Hasil penelitian ini sesuai dengan penelitian yang dilakukan Lustinayanti \& Kurniawati (2017) dalam judul "pengaruh waiting time terhadap kepuasan pelanggan pada industri perak di desa celuk sukawati gianyar bali" dengan output menunjukan hasil yang signifikan terhadap kepuasan pelanggan. Persamaan penelitian pada variabel X1, dan Variabel Y.

\section{Pengaruh lokasi terhadap kepuasan pelanggan pada Rumah Makan Gemah Ripah Purwakarta} Berdasarkan uji $\mathrm{T}$ yang telah dilakukan diketahui nilai $\mathrm{T}$ hitung untuk variabel lokasi (X2) sebesar T hitung 3,765 didukung dengan nilai signifikan 0,000 lebih kecil dari 0,05 atau 5\%, maka H0 ditolak H1 diterima, sehingga dapat dikatakan variabel lokasi (X2) mempunyai pengaruh yang signifikan terhadap kepuasan pelanggan (Y). Hasil penelitian ini sesuai dengan penelitian yang dilakukan (Muhtarom, Warso, \& Hasiolan, 2015) dalam judul "pengaruh kualitas 
pelayanan, harga dan lokasi terhadap kepuasan konsumen pada rumah makan Sbc Semarang" dengan output menunjukan hasil yang signifikan terhadap kepuasan pelanggan. Persamaan penelitian pada variabel X3, dan Variabel Y.

\section{Pengaruh waktu tunggu dan lokasi terhadap kepuasan pelanggan pada Rumah Makan Gemah Ripah Purwakarta}

Berdasarkan data primer (kuesioner) yang telah diolah oleh peneliti dengan bantuan SPSS 21, hasil penelitian ini menunjukan bahwa waktu tunggu dan lokasi bersama-sama (simultan) mempengaruhi kepuasan pelanggan, diketahui nilai koefisien regresi masing-masing variabel bebas memiliki tanda positif, hasil uji hipotesis dari uji $F$ menunjukan $F$ hitung sebesar 23,963 dengan taraf signifikan 0,000 yang lebih kecil dari 0,05 atau 5\%. Sehingga dapat disimpulkan bahwa secara simultan waktu tunggu (X1) dan lokasi (X2) berpengaruh signifikan terhadap kepuasan pelanggan (Y). Kedua variabel tersebut memiliki kontribusi terhadap kepuasan pelanggan. Jika pihak rumah makan mampu mempelajari kepuasan pelanggan dalam kedua variabel ini, maka akan semakin mendorong kesuksesan bisnisnya. Dalam penelitian ini baik secara parsial maupun simultan waktu tunggu (X1) dan lokasi (X2) berpengaruh positif terhadap kepuasan pelanggan $(\mathrm{Y})$.

\section{KESIMPULAN}

Berdasarkan hasil penelitian dan pembahasan yang telah dilakukan sebelumnya dengan bersandar pada masalah yang telah dirumuskan pada bab pendahuluan, maka dapat ditarik kesimpulan sebagai berikut:

a) Waktu Tunggu menunjukan adanya pengaruh yang positif dan signifikan terhadap Kepuasan Pelanggan pada rumah makan gemah ripah purwakarta. Sehingga dapat disimpulkan jika pihak rumah makan gemah ripah purwakarta memperhatikan waktu tunggu akan memberikan suatu dorongan positif kepada konsumen sehingga dapat meningkatkan kepuasan pelanggan.

b) Lokasi menunjukan adanya pengaruh yang positif dan signifikan terhadap Kepuasan Pelanggan, lokasi yang ada di rumah makan gemah ripah purwakarta baik. Hal tersebut disebabkan salah satunya karena arus lalu lintas menuju rumah makan lancar.

c) Ada pengaruh yang signifikan antara Waktu Tunggu dan Lokasi dengan Kepuasan Pelanggan. Sehingga dapat disimpulkan bahwa kedua variabel ini memiliki kontribusi terhadap Kepuasan Pelanggan yang terjadi di rumah makan gemah ripah purwakarta.

\section{REFERENSI}

Berman, B., Evans, J. R., \& Chatterjee, P. (2018). Retail Management: A Strategic Approach. United Kingdom: Pearson Education Limited.

Dabholkar, P. A. (2015). How to Improve Perceived Service Quality by Improving Customer Participation. In Proceedings of the 1990 academy of marketing Springer Publishing Company, LLC.

Ghozali, I. (2016). Aplikasi Analisis Multivarians Dengan Program IBM SPSS 23, Cetakan III. Semarang: Badan Penerbit Undip.

Heizer, J., \& Render, B. (2011). Operations Management. New Jersey: Prentice Hall.

Iqbal, Q., Whitman, L. E., \& Malzahn, D. (2012). Reducing Customer Wait Time at a Fast Food Restaurant on Campus. Journal of Foodservice Business Research, 15(4), 319334. $\quad$ https://doi.org/10.1080/1537802 0.2012 .706176

Iskandarsyah, N. M., \& Utami, S. (2017) Kepuasan Konsumen Pada Perumahan Murah Di Hadrah Property. Jurnal Ilmiah Mahasiswa Ekonomi Manajemen, 2(1), 129-141.

Kotler, P., \& Amstrong, G. (2016). Prinsip-prinsip Pemasaran. Jakarta: Erlangga.

Kotler, P., \& Keller, K. (2016). Marketing management (15 ed.). England: Pearson Education, Inc.

Kristanti, M., Redjo, O., \& Susilo, A. A. (2015). pengaruh perceived waiting time dan satisfaction with waiting environment terhadap waiting time satisfaction dan service satisfaction di restoran $X$ di Surabaya. Jurnal Hospitality dan Manajemen Jasa, 3(2), 102-112.

Lazuardi, M., \& Triady, M. S. (2015) Ekonomi Kreatif: Rencana Pengembangan Kuliner Nasional 20152019. Tim Studi dan Kementerian Pariwisata Ekonomi Kreatif. Jakarta: PT. Republik Solusi.

Levy, M., \& Weitz, B. A. (2012). Retailing Management. مدم مدمدم

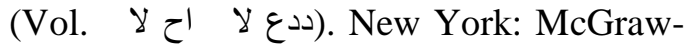
Hill/Irwin.

Lovelock, C. H., \& Wright, L. K. (2011). Managemen Pemasaran Jasa. Jakarta: Indeks (Gramedia Group).

Lustinayanti, W. E., \& Kurniawati, N. S. E. (2017). Pengaruh Waiting Time Terhadap Kepuasan, Loyalitas Dan Wom Pada Industri Perak Di Desa Celuk Sukawati 
Gianyar Bali. Jurnal Ekonomi dan Pariwisata, 12(1), 58-64.

Muhtarom, Warso, M. M., \& Hasiolan, L. B. (2015). Analisis Kualitas Pelayanan, Harga Dan Lokasi Terhadap Kepuasan Konsumen Pada Rumah Makan SBC Semarang. Journal of Management, 1(1), 1-9.

Oliver, R. L. (2010). Satisfaction: a behavioral perspective on the consumer. New York: M.E. Sharpe, Inc.

Polas, M. R. H., Rahman, M. M., Miah, M. A., \& Hayash, M. M. A. (2018). The Impact of Waiting Time towards Customers' Satisfaction in Fast Food Establishments: Evidence from Bangladesh. IOSR Journal of Business and Management (IOSR-JBM),
20(5), 11-21. https://doi.org/10.9790/487X2005021121

Silalahi, U. (2018). Metode Penelitian Sosial. Bandung: Refika Aditama.

Sugiyono. (2016). Metode Penelitian Kuantitatif, Kualitatif dan R\&D. Bandung: Alfabeta.

Tjiptono, F., \& Chandra, G. (2012). Pemasaran Strategik. Yogyakarta: Andi.

Tjiptono, F., \& Chandra, G. (2016). Service, Quality and Satisfaction (4 ed.). Yogyakarta: Andi.

Wu, J. R., Lu, S. G., \& Ge, Y. E. (2013). Time in High Density Passenger Flow Waiting Areas. Procedia - Social and Behavioral Sciences, 96(Cictp), 1801-1811. https://doi.org/10.1016/j.sbspro. 2013.08.205 